\title{
Writing skills enhancement for public health professionals in Rwanda
}

\author{
Raywat Deonandan' \\ Nodine Sangwa' \\ Steve Kanters ${ }^{2}$ \\ Sabin Nsanzimana ${ }^{3}$ \\ 'Interdisciplinary School of Health \\ Sciences, University of Ottawa, \\ Ottawa, ON, Canada; ${ }^{2}$ University \\ of British Columbia, Vancouver, BC, \\ Canada; ${ }^{3}$ Rwanda Biomedical Center, \\ Kigali, Rwanda
}

This article was published in the following Dove Press journal:

Advances in Medical Education and Practice

31 March 2017

Number of times this article has been viewed

Correspondence: Raywat Deonandan Interdisciplinary School of Health Sciences, University of Ottawa, 25 University Pvt, Ottawa, ON, Canada KIN 6N5

Tel + I 6135625800 Ext 8377

Email ray@deonandan.com
Abstract: In 2013, Canadian scholars delivered a 1-week workshop to 30 junior public health professionals in Rwanda. The goal was to improve the Rwandans' skills and confidence with respect to writing scientific papers for submission to international peer-reviewed global health journals. As a result of the workshop, there was a statistically significant improvement in participants' reported confidence in many aspects of navigating the publishing process, but no improvement in confidence regarding statistically analyzing their data. Remarkably, as a group, participants were able to write an article for a leading international journal, which was subsequently published. Results indicate that similar interventions would be both successful and well received, especially if targeted to individuals at a similar stage of career progress.

Keywords: education, Rwanda, public health, skills

\section{Introduction}

The "10/90 gap" is short form for the realization that $<10 \%$ of worldwide resources devoted to health research are put towards health in developing countries, where over $90 \%$ of all preventable deaths worldwide occur. ${ }^{1}$ Sub-Saharan Africa suffers most prominently from the 10/90 gap, due in large part to deficient research capacity in those countries. ${ }^{2}$ According to one study, sub-Saharan Africa produces $<1 \%$ of biomedical publications. ${ }^{3}$

Commonly, high-level research in low-income African countries is conducted by Western scientists who then publish their results in recognized international peerreviewed journals. Most empirical research in the field of global health is conducted in low-income countries, on the residents of those countries, and is most relevant to the policy needs of decision-makers in those countries. But the papers are written by the Western project leaders, published in Western journals, serve to elevate the global profiles of the Western authors, yet are ironically rarely accessible to the people or decision-makers in those same low-income countries, due to the publication pay walls often erected by the most prominent journals. ${ }^{4}$

This practice has been anecdotally justified in several ways, including that a publication history is more important for the career progress of Western authors; that since the Westerner often foots the lion's share of project funding, it stands to reason he should also be the one to benefit from the project's publication; and that the results of a study, regardless of who publishes it, will benefit all human beings.

The latter assumption has been widely contested. ${ }^{5}$ And emerging research capacity in low-income countries, particularly those in Africa, necessitates opportunities for 
African scholars to create career-building publishing histories. In the words of a South African writer, "we still need inventors; people who generate knowledge, intellectuals who lead in knowledge production". ${ }^{6}$ To fully emerge from so-called developing world status, low-income countries must develop a sustainable indigenous academic publishing tradition. "Publishing ensures transparency, demonstrates accountability for financial support, and allows for establishing metrics of productivity"?

The underrepresentation of scholars from low-income countries in the world of scientific publishing has been acknowledged since at least the $1970 \mathrm{~s} .{ }^{8}$ Unsurprisingly, there is a measured bias in the academic publishing world against manuscripts originating from low-income countries. ${ }^{9}$ In recent years, multiple strategies have been proposed to address the 10/90 gap. But despite the many capacity strengthening actions and achievements, the disequilibrium still persists. ${ }^{2}$

Building research capacity among African LMIC scholars has been identified as an important task closing the 10/90 gap. ${ }^{7}$ But the barriers to improving writing skills are multifactorial and historical, including fundamental weaknesses in general public education in several African countries. ${ }^{10}$

In 2012, The Rwanda Ministry of Health took an important step to put in place research guidelines for people who wish to conduct their research in Rwanda; most of the issues noted above were justified by the lack of policies and guidelines in many sub-Saharan African settings. For example, according to the Rwanda research guidelines, researchers coming from outside of Rwanda are requested to include a collaborator of Rwandan origin participating in all aspects of the study,

[with a clear repartition of responsibilities. As such, foreign investigators are requested to partner with a Rwandan researcher who is working in the field of research topic and help Rwanda build capacity for conducting research of its own]. ${ }^{11}$

One such capacity building action was a 1-week workshop in Kigali, Rwanda, targeted to established and emerging public health professionals with minimal to no experience in academic publishing. The purpose of the workshop was to empower these individuals with the skills and confidence to submit their research to high-quality international global health journals, thus accelerating and enhancing Rwanda's presence on the world's health research stage.

With this study, we present the quantitative and qualitative evaluation of that workshop and discuss strategies for future research capacity building opportunities for similar populations.

\section{Methods}

In August 2013, three scholars from the University of Ottawa and the University of British Columbia gave a 1-week workshop on high-level academic writing and publishing skills to 30 Rwandan public health professionals. The workshop arose from conversations between the Rwandan Ministry of Health, the University of Rwanda, and Dr Edward Mills of the University of British Columbia. Participants were either already employed by the Ministry of Health or were senior graduate students in the School of Public Health at the University of Rwanda in Kigali. All participants were involved in research projects that they wished to see translated into one or more publications in international peer-reviewed science journals.

The workshop consisted of 5 days of presentations and interactive exercises covering the following content: basic statistical analysis, the formal academic publishing process, how to communicate with editors, the parts of an academic paper, and strategies for organizing a paper's content. While the duration of the workshop was a function of limitations in resources and scheduling, week-long interventions are not unusual, with respect to skills development workshops in the global health and development domain. ${ }^{12,13}$

At the beginning of the workshop, all participants filled out a pre-session assessment questionnaire, which sought to measure their expectations for the workshop and their perceived baseline skills, with respect to their ability to statistically analyze data and present that analysis as a paper. A similar assessment questionnaire was given to the same participants at the end of the week.

Descriptive statistics were employed to determine whether self-perceived student skills had changed. Theme analysis was applied to written comments to qualitatively assess students' perceptions of the workshop's value.

Consent was received from the participants prior to the completion of the questionnaires. Participants were informed that the data were being collected both for evaluation and research purposes. This project received approval from the University of Ottawa Research Ethics Board (file H1 1-15-10).

\section{Results}

A plurality of participants $(41 \%)$ were most interested in publishing about HIV/AIDS research, and only five had ever been involved in writing an academic paper before. At the end of the week, $38 \%$ of respondents felt confident that they would be in a position to submit their paper to a refereed journal within 1 week's time.

As a result of the workshop, participants showed an improvement in confidence $(p<0.05)$ with respect to the 
following areas of academic writing: phrasing a good research question, selecting the right journal, understanding how journals select and evaluate submitted papers, writing an introduction to a paper, writing the methods section of a paper, writing the results section of a paper, writing the discussion section of a paper, understanding how to cite references in a paper, understanding the different types of academic papers (comment/editorial, review, original research, etc.), understanding how to write a paper in a compelling style, and understanding what an "impact factor" means and how it is calculated.

No significant improvement $(p>0.05)$ was seen with respect to confidence in analyzing and interpreting data, understanding what a $p$-value means in statistics, understanding what probability means, conducting analyses between two variables (e.g., using Student's $t$-test, chi-square, and correlation coefficients), conducting analyses using more than two variables (e.g., using logistic regression, analysis of variance and multiple regression), and using a statistics software package.

Qualitatively, the most emergent theme from the written comments, with respect to expectations for the workshop, was a general desire to improve writing skills. More specifically, many students expressed a desire to learn to navigate the formal publishing process and to get a better grasp of quantitative analysis, which they clearly understood is intimately tied with successful scientific publishing.

In terms of comments about the strengths and weaknesses of the workshop, the great majority (67\%) felt that the workshop was both useful and interesting. But the most common recommendations were to increase the length of the workshop beyond its 1-week length, and to add more time and content around statistical techniques.

On the final day of the workshop, participants successfully cowrote an opinion article that was submitted to, and subsequently published in, a leading international global health journal. ${ }^{14}$

\section{Discussion}

Participants reported significant improvement in their confidence around key aspects of scientific publishing, but no improvement in confidence around statistical analysis. These findings are not surprising, given that capacity building workshops and programs are known to be perceived to be very effective among research professionals. ${ }^{15}$ As well, effective teaching of statistical analysis is a challenge being experienced worldwide, ${ }^{16}$ and it is unrealistic to expect profound changes in statistical confidence after a single brief workshop.
We acknowledge that a proper ascertainment of participants' retention of the skills taught in the workshop should be applied several weeks after the workshop's conclusion. The present study is only able to measure participants' immediate perceptions of the value of the training sessions. However, the fact that they managed to publish a paper in a leading journal is compelling evidence that skills were indeed digested and used.

Known barriers to professional capacity building in African states include political will and the availability of trainers. ${ }^{17}$ In Rwanda, the will is present, but suitable trainers must be brought in from abroad. Sourcing Western colleagues to design and lead such workshops is prohibitively expensive. But there may be an opportunity for leveraging telecommunication technology to reduce cost, though the extent of that reduction remains in doubt. In addition, there is a growing number of researchers in Rwanda who can be used as catalysts for the cultivation of writing culture.

Rwanda is a popular target for research capacity-building projects, as several Western universities are involved with developing graduate training and medical student training. ${ }^{18}$ Local organizations, such as the The African Capacity Building Foundation, ${ }^{19}$ are spearheading efforts to catalyze African research capacity through investment in physical infrastructure and human resources. Much of the attention appears to be placed on opportunities to enhance skills at the school level. There remains an opportunity, however, to enrich the skills of mid- and senior-level professionals in situ.

Related are the Medical and Nursing Education Partnership Initiatives, President's Emergency Plan for AIDS Relief-funded initiatives developed to address the shortage of health care workers in sub-Saharan Africa. ${ }^{20,21}$ While those programs are geared toward specific clinical skills development, there is an opportunity to expand such training to include engagement with, and contribution to, the academic literature as foundational skills.

According to Trostle, ${ }^{22}$ effective research has four prerequisites: individual research skills and ability, appropriate infrastructure, relevance to national policies, and the ability to contribute to global research and policy needs. Infrastructural needs in low-income African countries are well demonstrated. Creative strategies for addressing the individual research skills gaps are now emerging and, as our results suggest, are very much in demand by the individuals best positioned to benefit from them.

Success in research capacity building in countries like Rwanda will depend not upon the enthusiasm of the target audience but upon political will, partnerships with external 
scholars, and dedicated programs to identify individuals in countries best positioned to capitalize on dedicated training. An investment in such research capacity can help to fill the 10/90 research gap, which in turn can lead to an improvement in overall professional capacities and therefore the ability of such professionals to better serve their communities.

\section{Acknowledgments}

The authors thank the following individuals for their invaluable contributions to this project: Dr Edward Mills, Dr Jeanine Condo, and Dr Agnes Binagwaho.

\section{Disclosure}

The authors report no conflicts of interest in this work.

\section{References}

1. globalforumhealth.org [homepage on the Internet]. Global Forum for Health Research. "10/90 gap"; 2011. Accessed October 27, 2016.

2. Kilama WL. The 10/90 gap in sub-Saharan Africa: resolving inequities in health research. Acta Trop. 2009;112 Suppl 1:S8-S15.

3. Rahman M, Fukui T. Biomedical publication--global profile and trend. Public Health. 2003;117(4): 274-280.

4. Deonandan R. The 10/90 Gap Is Holding Rwanda Back. The Huffington Post. 2013 Nov 4. Available from: http://www.huffingtonpost.ca/ dr-raywat-deonandan/1090-gap-rwanda_b_4203011.html. Accessed October 27, 2016.

5. Miranda JJ, Zaman MJ. Exporting 'failure': why research from rich countries may not benefit the developing world. Rev Saude Publica. 2010;44(1):185-189.

6. Msila V. Dark days for black researchers. Mail \& Guardian. 2015 Mar 6. Available from: http://mg.co.za/article/2015-03-06-dark-days-forblack-researchers. Accessed October 27, 2016.

7. Chu KM, Jayaraman S, Kyamanywa P, Ntakiyiruta G. Building research capacity in Africa: equity and global health collaborations. PLoS Med. 2014;11(3):e1001612.

8. Moravcsik MJ. Science in the Developing Countries: An Unexplored and Fruitful Area for Research in Science Studies. Journal of the Society for Social Studies of Science. 1985;3(3):2-13.
9. Yousefi-Nooraie R, Shakiba B, Mortaz-Hejri S. Country development and manuscript selection bias: a review of published studies. $B M C M e d$ Res Methodol. 2006;6:37.

10. Chokwe JM. Factors Impacting Academic Writing Skills of English Second Language Students. Mediterranean Journal of Social Sciences. 2013;4(14):377-383.

11. Republic of Rwanda, Ministry of Health. Guidelines for Researchers Intending to Do Health Research in Rwanda. Republic of Rwanda: Ministry of Health; 2012. Available from: http://www.moh.gov.rw/ index.php?id=131. Accessed February 16, 2017.

12. Makanjuola V, Doku V, Jenkins R, Gureje O. Impact of a one-week intensive 'training of trainers' workshop for community health workers in south-west Nigeria. Ment Health Fam Med. 2012;9(1):33-38.

13. Redman-MacLAren ML, MacLaren DJ, Solomon J, et al. Research workshop to research work: initial steps in establishing health research systems on Malaita, Solomon Islands. Health Res Policy Syst. 2010;8:33.

14. Rwandan Research and Implementation Writing Group. Building health research infrastructure in Rwanda. Lancet Glob Health. 2014; 2(1):e9-e10.

15. Shirey MR. Building scholarly writing capacity in the doctor of nursing practice program. J Prof Nurs. 2013;29(3):137-147.

16. Deonandan R. Strategies for Addressing Poor Statistical Literacy Among Scientists and Science Communicators. International Journal of Medical and Health Sciences Research. 2016;3(2):31-36.

17. Wubneh M. Building capacity in Africa: The impact of institutional, policy and resource factors. African Development Review. 2003; 15(2-3):165-198

18. globalstudies.gu.se [homepage on the Internet]. Building research capacity in Rwanda. University of Gothenberg. School of Global Studies; 2016 [updated March 30, 2016.] Available from: http://globalstudies. gu.se/english/cooperation/Rwanda. Accessed October 27, 2016.

19. African Capacity Building Foundation [homepage on the Internet]. Institute of Policy Analysis and Research Capacity Building Project (IPAR-CAP); 2016. Available from: http://www.acbf-pact.org/whatwe-do/how-we-do-it/grants/projects-regions/eastern-southern-africa/ rwanda/institute-policy. Accessed October 27, 2016.

20. Fogarty International Center [homepage on the Internet]. Medical Education Partnership Initiative (MEPI) [updated January 10, 2017]. Available from: https://www.fic.nih.gov/programs/pages/medicaleducation-africa.aspx. Accessed February 5, 2017.

21. pepfar.gov [homepage on the Internet]. PEPFAR. Nursing Education Partnership Initiative. Available from: https://www.pepfar.gov/partnerships/initiatives/nepi/. Accessed February 5, 2017.

22. Trostle J. Research capacity building in international health: definitions, evaluations and strategies for success. Soc Sci Med. 1992;35(11):1321-1324.
Advances in Medical Education and Practice

\section{Publish your work in this journal}

Advances in Medical Education and Practice is an international, peerreviewed, open access journal that aims to present and publish research on Medical Education covering medical, dental, nursing and allied health care professional education. The journal covers undergraduate education, postgraduate training and continuing medical education

\section{Dovepress}

including emerging trends and innovative models linking education, research, and health care services. The manuscript management system is completely online and includes a very quick and fair peer-review system. Visit http://www.dovepress.com/testimonials.php to read real quotes from published authors. 